\title{
Population Education for Better Quality Life
}

\author{
Ojo, Femi Taiwo
}

\author{
Department of Biology, School of Science, \\ Federal College of Education(Special), Oyo, Oyo State, Nigeria.
}

\section{Doi:10.5901/jesr.2013.v3n6p153}

\begin{abstract}
This paper, Population Education for Better Quality Life review the importance of Population Education when it reflects in the Curriculum of our Schools from Junior Secondary to Tertiary Institutions as this would guaranteed Better Quality life in terms of regulating human populations through the practice of methods that ensure proper family planning vis-a-vis food production. Better quality life is defined as a type of life in which the major needs of man whether physical, social and emotional are adequately satisfied. It further involves a standard of living that provides for adequate feeding, adequate clothing and adequate housing, together with other provisions in life that ensure adequate education, adequate health services, adequate leisure, that make possible the attainment of family welfare, social security, happiness and physical and mental well being of individual and his family. Iso, the aim of population education were listed and readiness of Male and Female for reproduction were also discussed with respect to Malthusian theory of population.
\end{abstract}

Keywords: Population, Curriculum, Family planning, Food, Reproduction.

\section{Introduction}

Even though many of the theories and postulates that are applicable to all living populations are equally applicable to man, man still retains a number of peculiarities. And in fact, in modern times, the issue of human populations all over the world has attracted so much attention, that it has particularly become imperative in developing countries to give the populace a much desired education about the main issues involved in human population. This is what has given rise to the subject of this course titled population education. Yisa (1988) cited UNESCO Dakar (1985), as having defined population education as "an educational programme (formal and non-formal), designed to create awareness and understanding of population issues directly related to social, economic and cultural development of the individual, the family, and the nation; to enable informed decision-making on population matters in order to contribute more effectively towards the amelioration of socio-economic and cultural welfare of the individual, the family and the nation".

\section{Nigeria as a Case Study}

In an awareness of the large young Nigerian population and the felt need for population education for the country, the Nigerian Educational Research Council (NERC) fomulated a comprehensive program on population education for both the in-school and out-of-school sectors of the country's education system in 1981. An expert steering committee sought to 1) define population education in the Nigerian context, 2) identify its goals, and 3) determine the major program areas which would become the foci of a population education project for Nigeria. The population education program seeks to increase awareness and understanding of 1 ) basic demographic processes as applied to one's family, community, the country, and the world; 2) effects of population change 
and growth on the social, economic, and environmental life of the society; 3) population and family size pressures on quality of life factors; and 4) population dynamics that the individual affects through personal behaviour. If population education is to reach the largest number of pupils in the in-school sector, it should be introduced at the elementary school level. Out-of-school education programs include adult education, literacy classes, labour training and education, agricultural extension classes, food and nutrition campaigns, mother and child health care, environmental education, and rural development programs. NERC hopes that through this population education program, all the decision making organs of the government will be sensitized on the interrelationships of demographic processes and the socioeconomic development of the nation. The council will ensure, through appropriate review of curriculum, that population education concepts are fully incorporated into the textbooks and other curriculum materials for use in schools. The following are the objectives of population education.

1. To provide knowledge and understanding of the prevailing situation.

2. Create awareness among the students about population matters, environment, and supply and demand of essential commodities.

3. Provide necessary skill to evaluate the impact and consequence of population growth on society.

4. To give the knowledge of population policy and population measures.

5. To provide the knowledge of causes of population growth and government's efforts to check it.

6. To develop awareness on the population dynamics.

7. To provide the knowledge of manpower management and resource development.

8. To enable students to know the merit of small family.

9. To know the causes of urbanization and its related problems.

10. To know about the causes of deforestation and ecological imbalance.

11. Understand the basic concept of population education from the view point of its nature, need and aims.

12. Acquire the skills of working with community to build awareness for the problem of population.

13. Acquire knowledge of various concepts and terminology of population, factors affecting population growth and scope of population education in school subjects.

14. Analyse and evaluate the growth of Nigeria population

15. Develop the ability to organise co-curricular activities and community resourced for promoting population education.

\section{Trend of Growth in World Human Population}

Records on human populations indicate that it is only in the early part of the 19th century that the human population in the world got to the 1 billion point. However, between the early part of the $19^{\text {th }}$ century and the next 100 years, the world human population has reached the 2 billion point. At about 1960, which was only about 50 years later, the human population in the world has reached 3 billion. By 1974, which is just about 14 years later, the world human population has reached 4 billion. By about the middle of 1987, (which is just about 13 years later), the world human population has reached 5 billion.(UNESCO)

\section{Trend of Growth in the Population of Nigeria}

As earlier noted, Nigeria is a typical example of the developing countries of the world, which records show account for about $90 \%$ of the growth in world human population (Yisa,1988). Nigeria is claimed to have an estimated population of 55.7 million in 1953. About 20 years later (specifically in 1973), this population according to records has risen to 79.0 million and it is projected that by 
year 2000, the Nigerian population is well over 150 million. This population growth rate is put at about $3.3 \%$. It must however be pointed out that issues of human populations which have now attracted much attention all over the world in recent times, have been such that have attracted the attention of biologically minded people all over the world for several generations before now. One of such people whose views on human populations are much respected even up till now was Reverend Thomas Malthus. population projections:

Projected population of the world, less developed countries, and more developed countries (high, medium, and low variants, AD 1985-2025).

\section{Malthus View on Human Population}

Malthus was a British Clergyman, whose full names were Reverend Thomas Robert Malthus. He lived between 1766 and 1834. He trained as a political economist, but later on became a Reverend Minister. His views on population growth and world economic development is now often referred to as Malthusian Theory of Population or Malthusian "Population Trap". Briefly his theory states that with the human population increasing at a geometrical rate, i.e., something similar to $1,2,4,8,16$, 32 etc, while food production is increasing at an arithmetic progression which is similar to $1,2,3,4,5$, etc, human population will soon outstrip food production. Consequently, starvation and poverty will set in unless human population growth is checked.

\section{Human Population and the Food Factor}

One major area of focus in human populations even in the olden days, was the issue of food factor in the growth of human populations. The importance of the food factor in human population growth cannot be under estimated. This importance was brought into the forefront in Malthusian Theory of Population. It is in modern times realized that except food production keeps pace with the rate at which human populations are growing there is likely to be starvation and abject poverty. The measures outlined below can however be taken to boost food production and by so doing cater for the nutritional needs of world human populations.

Improvement in agricultural methods that can improve food production.

The agricultural methods whose improvement can boost the production include crop rotation, mechanization of agricultural processes, breeding and introduction of new species, establishing large - scale plantations, adequate storage facilities, irrigation of farmlands and skillful use of fertilizers.

Large scale meat and fish production in order to raise the nutritional standard of the people.

Extensive research into alternative source of first class proteins, especially into the possibility of extracting these from plant materials.

The developed nations of the world can also intensify their aids through the appropriate agencies of United Nations to the poorer nations of the world. Such aids may include food materials, money, drugs and dressings and personnel.

\section{Conservation of the environment}

Exploration of new and acceptable sources of energy such as solar energy and tide power in agricultural processes.

\section{Sex education}

Sex education is concerned essentially with human sexuality, human reproduction and ethical issues bordering on sex related morality. Sex education programmes is designed to educate young people on the anatomy of male and female, the physiological processes involved in reproduction 
and the similarities and differences in the psychological behaviour of males and females to reproduction and other issues such as the ethics of sexual behaviour.

\section{Family planning}

Family planning is the group of services provided by some specialists through service delivery and counselling on issues bordering on fertility control. Family planning deals with issues such as birth planning, birth control, fertility regulation and use of contraceptive. Family planning essentially aims at enhancing the quality of life of the family. As such, it also has a part it can play in population education as it guaranteed better quality life- This is a type of life in which the major needs of man whether physical, social and emotional are adequately satisfied. It further involves a standard of living that provides for adequate feeding, adequate clothing and adequate housing, together with other provisions in life that ensure adequate education, adequate health services, adequate leisure, that make possible the attainment of family welfare, social security, happiness, physical and mental well being of individual and his family.

\section{Birth Control Methods}

Taking measures to control birth has become an imperative in most countries of the world because of a number of reasons, prominent among which are the following:

- The need to check the ever growing populations of the countries of the world, most especially the third world countries;

- The need to have the number of children each family can conveniently cater for;

- The need to space the children in such a way that will be convenient for the mother, the children and the family economy;

- The need to have children at a convenient time and in a convenient place when the parents can have enough attention for the children.

\section{Modern Birth Control Methods}

a. Natural methods, which include the following:
i. Abstinence
ii. Safe period
iii. Withdrawal (also known as coitus interruptus) and
iv. Lactational Amenorrhea method.

b. Artificial methods, which involve the use of certain materials as drugs or use of certain barriers which prevent the sperm of the man from meeting or fusing with the egg of the woman. These artificial methods include the following:
i. Use of condom
ii. $\quad$ Use of injectable contraceptives (simply known as injectables)
iii. Use of foaming spermicidal tablets (simply known as spermicides)
iv. Use of intral uterine device (simply known as I.U.D)
v. Use of oral contraceptives (simply known as Pills)
vi. Use of implant

\section{Readiness of Males and Females for Reproduction}

A large number of issues are involved in what we ordinarily term readiness of people for reproduction. Such issues include physical readiness, physiological readiness, emotional and psychological readiness, sociological readiness, educational readiness, economic readiness and religious readiness. These various form of readiness are discussed below. 
Physical readiness: Physical readiness of males and females for reproduction, involves the physical maturity of individuals, particularly the females to successfully carry the foetus for nine months and give birth to the child without much effort and without straining any of the body organs connected with the acts of reproduction, right from coition, through embryo development to parturition i.e., birth through the vagina. It is not just enough for the young males and females to show signs of puberty, which is manifested in the males in the bigger body build, stronger muscles, occasional erection of the penis, presence of the voice and occasional wet dreams and in the females in such things as bigger body build, stronger muscles, enlarged pelvic girdles, addition of the pad of fat to the buttocks, bigger breasts, presence of hairs in the armpit and pubic region. The females must in particular have their uterus, their pelvic girdles and the vagina in proper state of physical readiness for such reproductive activities as coition, growth of the foetus in the uterus and easy passage of the baby through the vagina during birth.

If any of these relevant reproductive organs is not physically ready, complications may set in at any stage during reproduction, for example, the coition may result in the tearing of the vagina, damage to the tube linking the vagina to the uterus, inability of the baby to have easy passage through the vagina during birth unaided and without undue strain and stress. Lack of physical readiness of the mother may occasionally result in the tearing of the vagina and much bleeding for the mother, particularly if the baby is fairly big.

Physiological readiness: Physiological readiness again has to do with the females. It is the state in which their primary and secondary reproductive organs and all other parts that are connected with the processes of reproduction, are sufficiently mature and are fully ready for the reproduction processes. This implies that these organs have grown fully and the organs are ready for the production of all secretions needed for the physiological processes involved in reproduction. The breast must be mature and in a state of readiness to locate efficiently and by so doing produce enough breast milk for the newly born baby. The vagina must be ready to produce appropriate fluid that will make coition easy and comfortable for both partners. All hormones needed for the maturation of the foetus must be secreted as at when due and in appropriate quantities.

Sociological readiness: Both the males and females must be sociological ready for reproduction, particularly the social responsibilities that accompany marital status and parenthood. They must not be the type that would be ashamed of carrying pregnancy and of carrying their babies or beast feeding them in the public in the full glare of other nursing mothers when they visit the ante natal clinics and when they visit the post natal clinics. They must be able to comfortably carry the babies on their back (as is the custom in Yorubaland). They must be ready to accommodate their in-laws, particularly those who come to assist them in the early stages of nursing the baby. They must be readily acceptable and accepted by their fellow nursing mothers. They must be ready to make appropriate sacrifices necessary as couples in the early stages of taking care of the pregnancy and in the stages involved in taking care of the babies. The females must shun bad habits, such as smoking, alcoholism and drug abuse. They must be ready to combine effectively family life with their career and social life. They must be ready to live together happily as husbands and wives. They must be sociologically ready to withstand occasional turbulent periods such as sickness of any member of the family, death or relations or friends et cetera.

Emotional and psychological readiness: Males and females should be emotionally and psychologically ready for the responsibilities of married life. They must know that reproduction and raring of children are not all beds of roses. They must never be seen to be feeling guilty of disappointing themselves, their parents, pastors, friends and close relations by their rushing into reproduction. Neither should they carry or nurse any sense of failure by their action. It is all such actions that do result in abandonment of children, early divorce, insecurity and withdrawal, all of which can result in depression, frustration and inability to give the babies their due attention and care.

Educational readiness: It is reasonable that both males and females are ready educationally for reproduction before they embark on it. This implies that both have either completed their 
education and are ready to take up available employment before they embark on reproduction. This is for the convenience of both partners and in particular, to let them have adequate opportunity of living together and taking care of their babies together. However, if all other factors involved in readiness for reproduction are right, educational readiness may not come into prominence. However, it is always in the interest of both males and females to be adequately qualified educationally, not necessarily to the same extent. Educational readiness influences the quality of care parents give to their children. It also influences the attitude of most children to education to a large extent.

Economic readiness: This is a very important factor in the readiness of males and females for reproduction. This is because it affects among other things the following:

a. Quality of life of the male and female involved;

b. Quality of life of their children;

c. Ability of both the male and female to attain greater height in life after the reproduction.

The main issues involved in economic readiness in a typical African setting include:

i. $\quad$ Ability to take care of themselves after reproduction;

ii. Ability to meet marital responsibilities to their families;

iii. Ability to meet parental responsibilities to the children;

iv. Ability to meet the needs of their immediate family in terms of feeding, clothing, housing et cetera.

v. Ability to meet the needs of extended family, which hitherto they were taking care of.

vi. Ability to meet social and religious obligation.

\section{Conclusion}

In the 20th century, population control proponents have drawn from the insights of Thomas Malthus, a British clergyman and economist who published An Essay on the Principle of Population in 1798. Malthus argued that, "Population, when unchecked, increases in a geometrical ratio. Subsistence increases only in an arithmetical ratio." He also outlined the idea of "positive checks" and "preventative checks." "Positive checks," such as diseases, war, disaster and famine, are factors that Malthus considered to increase the death rate. "Preventative checks" were factors that Malthus believed to affect the birth rate such as moral restraint, abstinence and birth control. He predicted that "positive checks" on exponential population growth would ultimately save humanity from itself and that human misery was an "absolute necessary consequence. Malthus went on to explain why he believed that this misery affected the poor in a disproportionate manner.

There is a constant effort towards an increase in population which tends to subject the lower classes of society to distress and to prevent any great permanent amelioration of their condition. The way in which these effects are produced seems to be this, we will suppose the means of subsistence in any country just equal to the easy support of its inhabitants. The constant effort towards population increases the number of people before the means of subsistence are increased. The food, therefore which before supplied seven millions must now be divided among seven millions and half or eight millions. The poor consequently must live much worse, and many of them be reduced to severe distress. Finally, Malthus advocated for the education of the lower class about the use of "moral restraint," or voluntary abstinence, which he believed would slow the growth rate and hence the need for population education.

\section{References}

Blackwell, 2001. Describes and explains the history of human population. Census Bureau.www. census.gov.

Frey, William H, et.al(2002).America by the Numbers: A Field Guide to the U.S. Population. New Press. Revealing guide to the myths and realities of American demographics. 
Gilbert, Geoffrey.(2001). World Population: A Reference Handbook. ABC-CLIO, Useful reference to current issues. Ideal for high school readers.

Hohm, Charles F. et.al. (2000).Population. Addresses and debates issues concerning world population and its effects on the environment. Livi-Bacci, Massimo.Trans. Carl Ipsen. A Concise History of World Population. 3rd ed. "http://www.population" http://www. population action.org

Malthus, Thomas.Ed.et. al (1993). An Essay on the Principle of Population. Oxford University Press. This classic treatise presents poverty as the result of the population increasing faster than the world's resources.

Nathan Keyfitz,(1982). Population Change and Social Policy, a compendium of insightful essays. The 1984 issue of the annual World Development Report of the World Bank focuses on population changes in underdeveloped countries.

Rohe, John F. A(1997) Bicentennial Malthusian Essay: Conservation, Population, and the Indifference to Limits. Rhodes \& Easton. Presents in today's context the themes Malthus sounded 200 years ago.

Raymond F. Dasmann,(1984) Environmental Conservation, 5th ed, a study of the human influence on nature and its consequences for human opulation

Solomon,M.E.(1966).Population Dynamics.

Teitelbaum, Michael S.(1998). A Question of Numbers: High Migration, Low Fertility, and the Politics of National Identity. Hill \& Wang. Problems stemming from population decline.

UNESCO Dakar(1985).

Yisa B.(1988).Introduction to Population Education. 